\title{
Effects of PI3K and FSH on steroidogenesis, viability and embryo development of the cumulus-oocyte complex after in vitro culture
}

\author{
Danielle Kaiser de Souza ${ }^{1,5}$, Loise Pedrosa Salles ${ }^{2,4}$, Ricardo Camargo ${ }^{3}$, \\ Laura Vanessa Mourão Gulart ${ }^{2}$, Suellen Costa e Silva ${ }^{2}$, Beatriz Dolabela de Lima ${ }^{3}$, \\ Fernando Araripe Gonçalves Torres ${ }^{4}$ and Alzira Amélia Martins Rosa e Silva ${ }^{1}$ \\ Laboratory of Health Biotechnologies - Faculty of Medicine, University of Brasilia; Laboratory of Microbiology, Department \\ of Cellular Biology - Institute of Biology, University of Brasilia; Laboratory of Molecular Biology, Department of Cellular \\ Biology - Institute of Biology, University of Brasilia; and Faculty of Ceilandia, University of Brasilia, Brazil
}

Date submitted: 24.04.2017. Date revised: 27.10.2017. Date accepted: 07.11.2017

\section{Summary}

The purpose of this study was to evaluate the effects of FSH and PI3K on the nuclear maturation, viability, steroidogenesis and embryo development of bovine cumulus-oocyte complexes (COCs). Oocyte maturation was achieved with MIV B, MIV B+100 $\mu$ M LY294002, MIV B+10 ng/mL follicle stimulating hormone (FSH), or MIV B+10 ng/mL FSH+100 $\mu \mathrm{M}$ LY294002 treatments for 22-24 h. After the cultured COCs were denuded, oocytes were separated into those that extruded polar bodies (mature) and those that did not, and real-time polymerase chain reaction (PCR) for BAX, BCL2, LHR, FSHR, CYP11A1, CYP19A1 and HSD17B1 genes was performed. The culture medium was collected to determine the levels of $17 \beta$-estradiol (E2) and progesterone (P4). The trypan blue test was used to study COC viability, and embryo development was evaluated. FSH increased nuclear maturation and PI3K blocked the maturation but did not influence oocyte viability. BAX and BCL2 expression levels in the cumulus cells were only affected by FSH, and the BAX levels decreased after treatment with LY294002. FSH increased the levels of E2 and P4, however inhibition of PI3K decreased E2 levels. MIV B enhanced levels of LHR, FSHR, CYP11A1, CYP19A1 and HSD17B1, whereas LY294002 inhibited the expression levels of all genes. MIV B+FSH decreased the expression levels of all genes except CYP11A1. LY294002 did not demonstrate any effects in the presence of FSH. Embryo development was significantly decreased when the MIV B+FSH medium was used. In conclusion, FSH controls the steroidogenesis, viability and gene expression in COCs. PI3K plays essential roles in nuclear maturation, steroidogenesis and embryo development.

Keywords: COC, Embryo development, FSH, PI3K, Steroidogenesis, Viability

\footnotetext{
${ }^{1}$ All correspondence to: Alzira A.M. Rosa e Silva or Danielle Kaiser de Souza. Campus Darcy Ribeiro, Faculdade de Medicina - Universidade de Brasilia 70910-900, Brazil. Email: aamresil@gmail.com or dany.kaiser@gmail.com

${ }^{2}$ Laboratory of Health Biotechnologies - Faculty of

Medicine, University of Brasilia.

${ }^{3}$ Laboratory of Microbiology, Department of Cellular Biology - Institute of Biology, University of Brasilia, Brazil. ${ }^{4}$ Laboratory of Molecular Biology, Department of Cellular Biology - Institute of Biology, University of Brasilia, Brazil. ${ }^{5}$ Faculty of Ceilandia, University of Brasilia, Brazil.
}

\section{Introduction}

Ovarian follicles are the fundamental units of the reproductive cycle and are responsible for gametogenesis and steroidogenesis. Oocytes are attached to and are surrounded by granulosa cells, which form the cumulus-oocyte complex (COC), and by theca cells (Morgan et al., 2015; Zhang \& Liu, 2015). The maturation process of the oocyte includes both the nuclear (meiosis) and cytoplasmic maturation processes (reorganization of organelles and cytoskeleton, transcription of RNAs, and translation of proteins related to embryonic development) (Ferreira et al., 2009). The in vitro viability of COCs is essential for 
embryo development and is affected by the pubertal status of the female (Pawlak et al., 2015) and FSH levels, which maintain the expression of $B A X$ and $B C L 2$ genes in the granulosa cells (Mani et al., 2010).

Steroidogenesis is one of the most important and well known factors involved in oocyte maturation both in vivo and in vitro. The intrafollicular concentrations of progesterone and 17 $\beta$-estradiol are important to the oocyte's competence in generating embryos after in vitro fertilization (Aardema et al., 2013) and affect the expression of zona pellucida proteins (Kempisty et al., 2012). Supplementing the COC culture medium with $17 \beta$-estradiol and progesterone improves the rate of embryos that develop to the morula stage, compared with medium containing only LH and FSH (Zheng et al., 2003). Higher in vitro concentrations of estradiol increased chromosomal aberrations of oocytes and diminished embryo development, whereas the addition of FSH reversed both effects (Beker et al., 2002).

In addition, $17 \beta$-estradiol influences the viability and oxidative stress levels of cultured neurons by suppressing Bax and stimulating Bcl-2 expression levels (Li et al., 2013a; Li et al., 2013b). Phosphatidylinositol 3-kinase (PI3K) is essential for the viability effects of $17 \beta$-estradiol, and similarly, steroidogenesis is influenced by the levels of PI3K and the gonadotropins $\mathrm{LH}$ and FSH.

PI3K family proteins, which were discovered in 1980 (Liu et al., 2009), are kinases that phosphorylate 3'hydroxyl inositol groups found in membrane lipid molecules known as phosphatidylinositols to generate phosphatidylinositol 3,4,5-trisphosphate $\left(\mathrm{PIP}_{3}\right)$ and other phosphatidylinositol phosphate molecules. The latter components recruit $\mathrm{AKT} / \mathrm{PKB}$ to activate intracellular cascades that control growth, proliferation, survival/viability, metabolism, intracellular trafficking, and differentiation of cells (Hawkins et al., 2006; Engelman et al., 2006; Yuan \& Cantley, 2008; Liu et al., 2009; Vanhaesebroeck et al., 2010).

PI3K proteins are classified into three different classes according to phosphorylation substrates and regions of sequence homology as follows (Hawkins et al., 2006; Engelman et al., 2006): classes I (A and B), II and III; however, the last two classes are not completely understood. Class I is related to cell surface receptors; class II seems to be related to the internalization of receptors, cellular migration, glucose metabolism, exocytosis, apoptosis; and class III controls the intracellular transport of vesicles in the Golgi apparatus, cellular growth and autophagy (Engelman et al., 2006; Vanhaesebroeck et al., 2010).

Class I proteins are clearly related to intracellular signalling, and the subtype IA proteins are activated by tyrosine kinase receptors and use p85 as the regulatory subunit, whereas subtype IB proteins are activated by G-protein-coupled receptors and do not use p 85
(Vanhaesebroeck et al., 2010). The catalytic subunit can be $\mathrm{p} 110 \alpha, \mathrm{p} 110 \beta, \mathrm{p} 110 \gamma$ or $\mathrm{p} 110 \delta$ and promotes the activation of complex intracellular signalling using proteins including $\mathrm{AKT} / \mathrm{PKB}, \mathrm{FOXO}, \mathrm{PDK} 1$, mTOR, MAPK and others (Engelman et al., 2006; Vanhaesebroeck et al., 2010; Zheng et al., 2012).

PI3K proteins participate in the activation and survival of primordial follicles and in the recruitment of follicles in ovarian cycles (Zheng et al., 2012). FSH activates cAMP/PKA and PI3K, resulting in the increase of aromatase (CYP19) expression (Stocco, 2008). Aromatase converts androgens into estradiol, enhances the effects of FSH on COCs and progresses ovarian follicle development to a preovulatory stage (Stocco, 2008).

The effects of PI3K have been mostly evaluated in granulosa cells but not in bovine COCs. The aim of the present study was to analyze the in vitro effects of PI3K and its relationship to the effects of FSH on COC maturation, viability, steroidogenesis and embryo development. An inhibitor of PI3K, LY294002, was used to understand the intracellular effects of PI3K in vitro. It is noteworthy that oocytes were completely viable after culture, based on trypan blue tests, and viability, steroidogenesis and embryo development were significantly affected by PI3K.

\section{Materials and methods}

Bovine ovaries were obtained from a local slaughterhouse (Distrito Federal, Brazil) and transported to the laboratory in sterile saline solution $(0.9 \% \mathrm{NaCl}, \mathrm{w} / \mathrm{v})$ at $35-37^{\circ} \mathrm{C}$. The ovaries were rinsed twice in saline solution to remove the blood and were maintained at $35-37^{\circ} \mathrm{C}$.

Follicles ( 1 to $8 \mathrm{~mm}$ in diameter) were aspirated with 21-gauge needles to obtain immature COCs. Ovarian follicles with clear fluid and well vascularized appearance were selected. The COCs were suspended in phosphate-buffered solution (PBS) (Invitrogen, Brazil) and BSA (Sigma, USA) under sterile conditions, and those characterized by compact cumulus cells and evenly granulated cytoplasm were selected (Viana et al., 2004).

After selection, COCs were cultured in defined, patented, serum free, basic maturation in vitro medium (MIVB) [applicant: Fundação Universidade de Brasilia]. MIVB is composed of a diluent alpha-MEM medium (Invitrogen-GIBCO, Brazil), HEPES (Sigma, USA), sodium bicarbonate, polyvinyl alcohol (PVA), non-essential amino acids, transferrin (InvitrogenGIBCO, Brazil), $10^{-7} \mathrm{M}$ androstenedione, and antibiotics, penicillin and streptomycin, supplemented with or without FSH $10 \mathrm{ng} / \mathrm{mL}$ (Sigma, USA). The inhibitor LY294002 (Sigma, USA) was used to determine the role of PI3K. 


\section{Experimental design}

The experimental groups were MIVB with no FSH (0FSH), MIVB with no FSH supplemented with 10 $\mu \mathrm{M}$ or $100 \mu \mathrm{M}$ of LY294002 (0FSH 10LY and 0FSH 100LY, respectively), MIVB with FSH $10 \mathrm{ng} / \mathrm{ml}$ (10FSH) and MIVB with FSH $10 \mathrm{ng} / \mathrm{ml}$ and $10 \mu \mathrm{M}$ or 100 $\mu \mathrm{M}$ of LY294002 (10FSH 10LY and 10FSH 100LY, respectively). The doses of LY294002 were based on a study conducted by Hoshino et al. (2004). The group with the $10 \mu \mathrm{M}$ dose was excluded from PCR assays and polar body extrusion rate determination because it did not demonstrate any effects.

All experiments procedures after in vitro maturation was based on the idea of comparing oocytes that matured in vitro with those ones that did not mature (extrude polar body) in terms of viability and gene expression.

\section{In vitro maturation of COCs and the viability test}

COCs (35-40 COCs/well) were cultured in $400 \mu \mathrm{l}$ of medium for $22-25 \mathrm{~h}$ at $38.5^{\circ} \mathrm{C}, 5 \% \mathrm{CO}_{2}$, and 95\% humidity. The trypan blue exclusion test was performed to determine oocyte viability before and after culture, and no non-viable oocyte was found. Viability of COCs was also evaluated by embryo development in vitro.

The maturation rates were determined by the polar body extrusions after in vitro culture and were expressed as the average of percentages of matured oocytes per experiment.

\section{In vitro fertilization and embryo culture}

After culture, the COCs were fertilized according to the methods described by Mota et al. (2015), and embryo culture was performed using SOF medium as described by Gulart (2015).

\section{Hormone level measurement}

The activity of steroidogenesis was assessed by the measurement of hormones in the medium after culture. The culture medium of each well was collected and frozen at $-20^{\circ} \mathrm{C}$ until hormone level analysis. Chemiluminescence was performed to measure $17 \beta$ estradiol (E2) and progesterone (P4) concentrations. The concentrations of both hormones were expressed as $\mathrm{ng} / \mathrm{ml}$, and the values were used to determine the $\mathrm{E} 2 / \mathrm{P} 4$ ratios for each sample.

\section{Isolation of cumulus cells and oocytes (polar body extrusion) after culture}

After culture, the COCs were mechanically denuded and oocytes were isolated from cumulus cells. Isolated cumulus cells were centrifuged twice in PBS for $5 \mathrm{~min}$ at $6000 \mathrm{rpm}$. The oocytes and the pelleted cumulus cells were resuspended in PBS and TRIzol Plus (Life Technologies, Brazil) and stored at $-80^{\circ} \mathrm{C}$ until RNA extraction.

The oocytes were divided into two categories: oocytes that matured and extruded polar bodies (progressed to metaphase II) and immature ones that did not extrude polar bodies [germinal vesicle/germinal vesicle breakdown (GV/GVBD), metaphase, anaphase or telophase I)]. The rate of polar body extrusion was correlated to $17 \beta$-estradiol (E2) and progesterone (P4) concentrations in the medium.

\section{RNA extraction from cumulus cells}

The TRIzol Plus (Life Technologies, Brazil) protocol was used for total RNA extraction. The isolated RNA was resuspended in RNase and pyrogen free water (Invitrogen) and stored at $-80^{\circ} \mathrm{C}$. RNA concentration and quality were measured using the NanoDrop 2000/2000c (Thermo Fisher Scientific) and 2100 Bioanalyzer (Agilent Technologies). The samples that presented NanoDrop $\mathrm{A}_{260} / \mathrm{A}_{280}$ ratios between 1.8 to 2.0 were used to synthesize cDNA samples.

\section{cDNA synthesis and real-time PCR}

The QuantiTect Reverse Transcription (Qiagen, USA) kit was used to perform cDNA synthesis based on the manufacturer's instructions, and the resulting samples were stored at $-20^{\circ} \mathrm{C}$.

Real-time PCR reactions were performed using the SYBR® Green Master Mix (Applied Biosystem, USA) with 50-100 ng/ $\mu$ l of cDNA, RNase and pyrogen free water (Invitrogen), and primer mixes that contained $100 \mathrm{nM}$ forward and $100 \mathrm{nM}$ reverse primers in the final volume of PCR reaction. The primers (Table 1) were designed based on the GenBank code and using the IDTSci Tools (Integrated DNA Technologies, USA), which included BLAST analysis. The real-time PCR conditions were previously standardized to guarantee high efficiency.

The cycling conditions included the following steps: $95^{\circ} \mathrm{C}$ for $20 \mathrm{~min}, 45-50$ cycles of $95^{\circ} \mathrm{C}$ for $3 \mathrm{~s}$, and $60^{\circ} \mathrm{C}$ for $30 \mathrm{~s}$, as described for the Fast SYBR® Green Master Mix. The melting curves confirmed that a single specific product was generated for each target gene, and no-template controls showed the absence of contaminants.

The relative quantification was calculated using the $\Delta \Delta \mathrm{CT}$ method, and cyclophilin A (CYC) was chosen as the reference gene. The mean and standard deviation (SD) of CTs were $22.9( \pm 2.07, \mathrm{SD})$ for cumulus cells, and $32.68( \pm 2.86, S D)$ for oocytes. The calibrator group was the immature cumulus cells obtained from noncultured COCs (GV). Three or four biological samples from each experimental group, and three or four 
Table 1 Sequences and temperature melting of target bovine gene primers

\begin{tabular}{lllcl}
\hline Gene & \multicolumn{2}{c}{ Primers sequence } & $\mathrm{T}_{\mathrm{m}}$ & GenBank code \\
\hline CYC & F: TGGCAAGTCCATCTATGGCGAGAA & R: ATCCAACCACTCAGTCTTGGCAGT & 77.39 & NM_178320 \\
FSHR & F: AGAAGAAAGCAGGTGGATGG & R: GTTAGAGCAGTGACAGAGTCG & 79.78 & NM_174061 \\
LHR & F: TGAAAGCACAGCAAGGAGAC & R: GGAGTGTCTTGGGTAAGCAG & 72.17 & U20504 \\
CYP11A1 & F: GCTCCAGAGGCAATAAAGAAC & R: GATGTCCCCTACAAACTTTCCG & 79.48 & NM_176644 \\
CYP19A1 & F: CTTGGGCTATGTGGACGTG & R: CCCCTGGATGTTAACCACG & 69.05 & U18447 \\
HSD17B1 & F: CCGTCCCAGAGCTTCAAAG & R: GAATCTGCATCCCTCACGTC & 83.79 & NM_001102365 \\
BAX & F: GTTGTCGCCCTTTTCTACTTTG & R: AAGGAAGTCCAATGTCCAGC & 79.81 & NM_173894 \\
BCL2 & F: CCCTGT TTGATTTCTCCTGGCTGT & R: TGGGCTTCACTTATGGCCCAG ATA & 80.81 & NM_001166486 \\
\hline
\end{tabular}

FSHR: FSH receptor; LHR: LH receptor; CYP11A1: cytochrome P450, family 11-A1; CYP19A1: aromatase; HSD17B1:

hydroxysteroid dehydrogenase $17 \beta$ 1; CYC: cyclophilin A (peptidylprolyl isomerase A); BAX: BCL2 associated X; BCL-2: B cell CLL/lymphoma-2. $\mathrm{T}_{\mathrm{m}}$ : melting temperature $\left({ }^{\circ} \mathrm{C}\right)$.

replicates per biological sample, were analysed using PCR reactions.

A biological sample contained 15-25 oocytes or cumulus cells from 25 oocytes (each oocyte contains approximately $10^{5}$ cumulus cells) (Calado et al., 2005). The COC pool was cultured for $24 \mathrm{~h}$ and after denudation, were grouped into oocytes that either extruded polar bodies and those did not. The cumulus cells were not separated based on the oocyte maturation state to avoid degeneration.

\section{Statistical analysis}

The chi-squared test was performed to analyze oocyte maturation (polar body extrusion). Two-way analysis of variance (ANOVA), followed by one-way ANOVA and the Bonferroni post hoc test were performed to analyze hormone measurements and E2/P4 ratios. Student's $t$-test was performed to determine the significant differences in the hormone measurements and $\mathrm{E} 2 / \mathrm{P} 4$ ratios in the culture medium between the groups. The Kruskal-Wallis followed by StudentNewman-Keuls tests were performed to determine the differences in real-time PCR analysis among the groups.

The correlation between $17 \beta$-estradiol or progesterone and the nuclear maturation was evaluated by simple linear regression and Pearson's correlation. The differences were considered significant when the $P$ value was $<0.05$.

\section{Results}

Medium supplemented with FSH significantly increased polar body extrusion compared with all groups, and PI3K inhibition blocked polar body extrusion of COCs cultured in 10FSH medium (Fig. 1). Interestingly, no degenerated COCs or oocytes were observed after culture. Only a few cumulus cells of one COC were degenerated and detached after culture (Figure S1). BAX and BCL2 gene expression levels were also tested in the cumulus cells and oocytes from cultured COCs and were differentially regulated based on the cell type (Figs 2 and 3).

In cumulus cells, both $B C L 2$ and $B A X$ expression levels were upregulated by FSH, however PI3K affected only $B A X$ expression levels (Fig. 2). The oocytes expressed lower levels of $B C L 2$ with the exception of immature oocytes cultured in the 0FSH 100LY medium (Fig. 3). Oocytes also expressed significantly lower levels of BCL2 mRNA compared with cumulus cells (data not shown; $P<0.05$ ).

The $B A X$ expression levels of oocytes (Fig. 3) are similar to those of cumulus cells (Fig. 2; $P>0.05$ ); however, higher levels of mRNA were observed in both matured and immature oocytes after $24 \mathrm{~h}$ of culture (Fig. 3; $P>0.05$ ).

In terms of steroidogenesis, FSH supplementation in the medium significantly enhanced the concentrations of E2 and P4; however, it is noteworthy that $0 \mathrm{FSH}$ medium was also able to sustain steroidogenesis (Table 2) in the presence of androstenedione. PI3K inhibition (100 $\mu \mathrm{M}$ of LY294002) significantly decreased E2 production and E2/P4 ratios in the $0 \mathrm{FSH}$ and 10FSH groups, whereas PI3K inhibition enhanced P4 production only in the OFSH medium (Table 2). Progesterone did not demonstrate any relationship with polar body extrusion $\left(\mathrm{R}^{2}=0.009, P=0.73\right)$; however, $17 \beta$-estradiol showed a significant correlation to nuclear maturation and polar body extrusion $\left(\mathrm{R}^{2}=\right.$ $0.564, P=0.0020)$. The results demonstrate the essential role of PI3K in the steroidogenesis of COCs in vitro.

Based on the activity of steroidogenic pathways as evaluated by E2 and P4 concentrations, the gene expression levels were evaluated after culture. The culture medium, absent of FSH (OFSH), enhanced the gene expression levels of $L H R$ (Fig. 4A), FSHR (Fig. 4B), CYP11A1 (Fig. 5A) and CYP19A1 (Fig. 5B), but did not change the expression of $H S D 17 B 1$, compared with the 


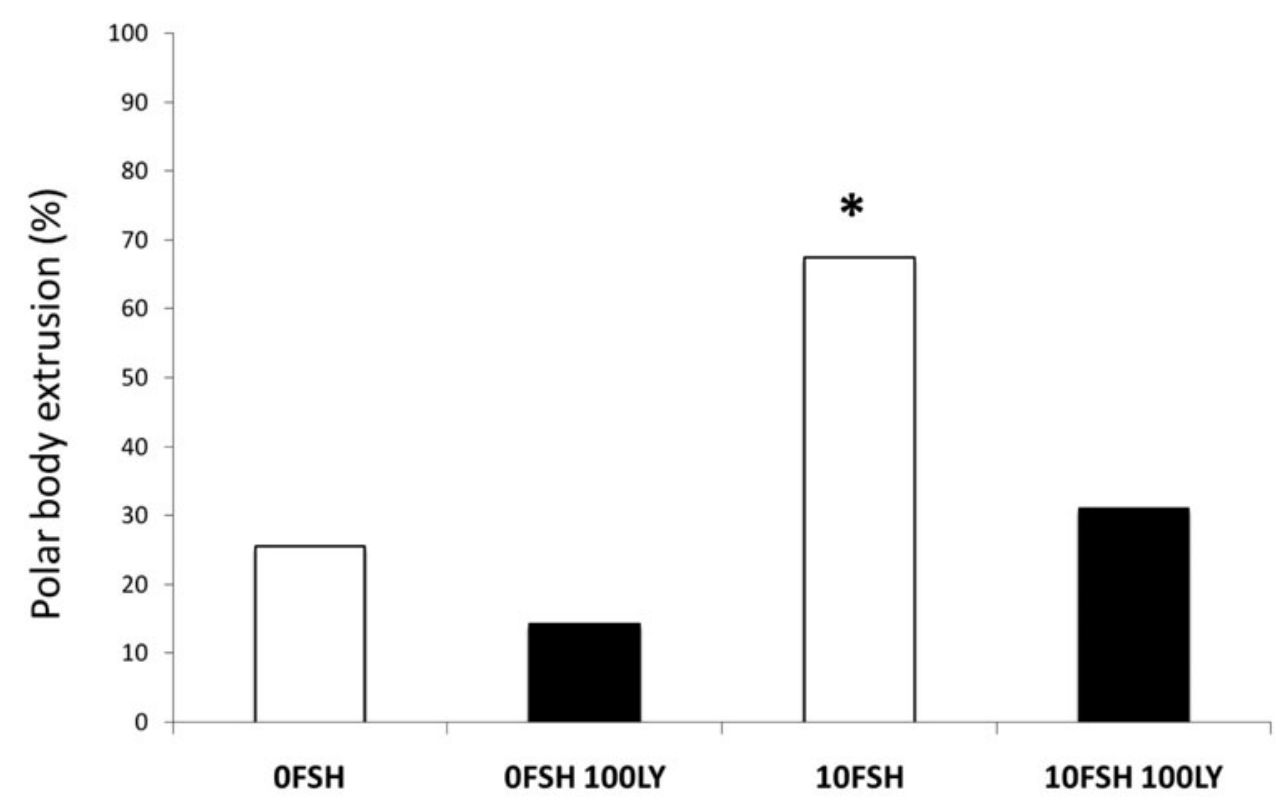

Figure 1 Effects of FSH and PI3K inhibitor, LY294002, on polar body extrusion of oocytes isolated from bovine COCs that were matured in vitro. Oocytes per treatment 0FSH: 51 oocytes; 0FSH 100LY: 42 oocytes; 10FSH: 44 oocytes; 10FSH 100LY: 73 oocytes. The result was obtained from three independent experiments (replicates) of IVM. *Statistical difference from all groups (chi-squared test, $P<0.05$ ). Values are expressed as averages of the maturation percentages of each experiment.

$10 \mathrm{FSH}$ group. In contrast, the 10FSH group presented lower levels of LHR, FSHR, CYP19A1 and HSD17B1 expression levels (Figs 4 and 5).

PI3K inhibition decreased the expression of $L H R$ (Fig. 4A), FSHR (Fig. 4B), CYP11A1 (Fig. 5A), CYP19A1 (Fig. 5B) and HSD17B1 (Fig. 5C) when 0FSH medium was used. The FSH action was not affected by PI3K inhibition after $24 \mathrm{~h}$ of culture (Figs 4 and 5).

The in vitro rates of embryo development were similar to those described by Mota et al. (2015), and no differences were observed between $0 \mathrm{FSH}$ and $0 \mathrm{FSH}$ 100LY groups (Fig. 6). 10FSH was able to increase embryo cleavage but not blastocyst development, and 10FSH 100LY decreased the cleavage and blastocyst production in vitro (Fig. 6). These results indicate the relevance of FSH to embryo development and show that PI3K alters FSH action in embryo development.

\section{Discussion}

PI3K influenced nuclear maturation and blocks FSH effects in polar body extrusion, and PI3K inhibition did not degenerate oocytes after culture, despite changes in the gene expression levels of $B A X$ and $B C L 2$ in oocytes and cumulus cells. Steroidogenesis, mostly 17betaestradiol, was also influenced by PI3K; it was not so clear, however, how the interactions between FSH and
PI3K influenced gene expression. Similarly, estrogen was correlated to polar body extrusion, as well as PI3K and FSH. Interestingly, FSH increased embryo cleavage and the inhibition of PI3K severely decreased blastocyst development in vitro. To our knowledge, this is the first paper that describes the relevance of PI3K to bovine COCs in vitro.

Oocyte maturation corresponds to nuclear (polar body extrusion) and cytoplasmic maturation, which includes the production of RNAs and proteins for embryo development (Ferreira et al., 2009). Polar body extrusion is strongly influenced by FSH (Mota et al., 2015) and PI3K. The F-actin in oocytes is dependent on PtdIns $(3,4,5) \mathrm{P3}$, which is produced by proteins such as PI3K. The inhibition of PtdIns production modifies the migration of the meiotic fuse to the peripheric oolemma (Zheng et al., 2013) and could potentially explain the inhibition of polar body extrusion by LY294002 even in the presence of FSH in the medium.

Despite the nuclear maturation results, viability was not influenced by PI3K in vitro as shown by the trypan blue test. The PI3K/AKT proteins control apoptosis, and LY294002 increased the number of dead cumulus cells from porcine COCs cultured with FSH (Shimada et al., 2003). In addition, BAX and BCL2 levels of the oocytes were not strongly modulated by PI3K, and the cumulus cells were very responsive to FSH and PI3K. As previously described, the BAX and BCL2 levels of the granulosa cells are controlled and stimulated 


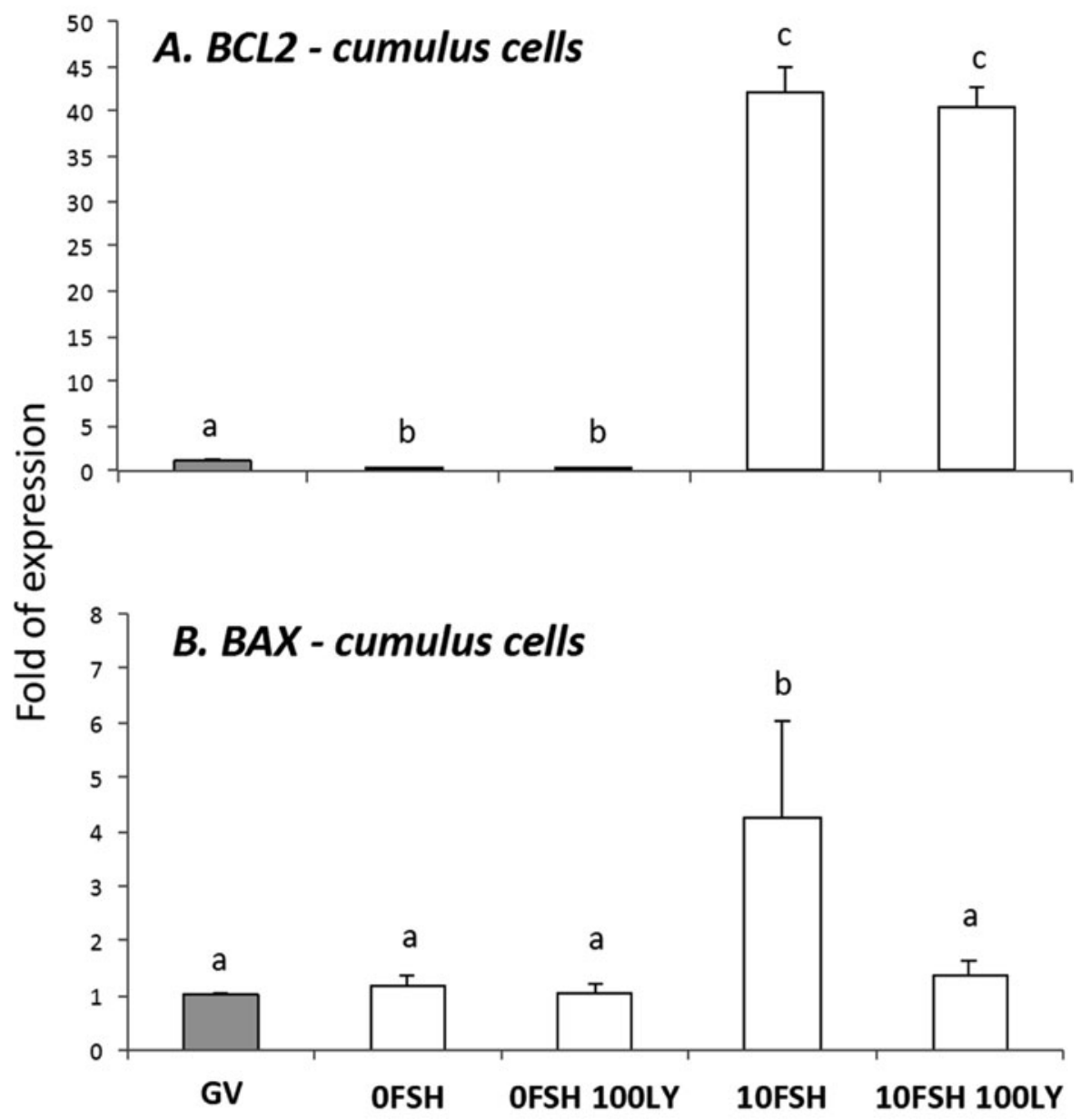

Figure $2 B A X$ and BCL2 gene expression levels in cumulus cells isolated from COCs after being cultured in a medium with or without FSH and PI3K inhibitor, LY294002. ${ }^{a, b, c}$ Different letters indicate significant statistical differences among groups $(P<$ $0.05)$.

by FSH, and only BAX levels respond to PI3K (Mani et al., 2010); this is similar to the results presented here.

The viability of cultured cells is clearly influenced by 17 $\beta$-estradiol ( $\mathrm{Li}$ et al., 2013a, b). Higher concentrations of $17 \beta$-estradiol in the COC culture medium $\left(10^{-4} \mathrm{~mol} / \mathrm{l}\right)$ significantly increased oocyte diameter, nuclear maturation and cumulus expansion in porcine oocytes (Kubo et al., 2015); however, higher rates of chromosomal aberrations were identified in bovine oocytes (Beker et al., 2002). Progesterone and estradiol also influenced the expression of zona pellucida glycoproteins in canine oocytes (Kempisty et al., 2012), demonstrating the relevance of progesterone and estradiol to the fertilization process.

The 0FSH medium was able to sustain steroidogenesis based on androstenedione precursor and, as expected, the addition of FSH enhanced its ability. The patented MIV B medium is different from MIV C due to its lack of hormones as shown in a previous analysis (Vasconcelos et al., 2013). MIV C was described as a pro-estrogenic medium in a study in which the wall sections of bovine ovarian follicles were cultured in vitro with medium containing no $\mathrm{FSH}$ and supplemented with androstenedione and other hormones (Vasconcelos et al., 2013). The MIV B medium is also estrogenic and sustains COCs in vitro even when FSH is absent (E2:P4 ratio is approximately 1.0).

FSH is a well known hormone related to follicle steroidogenesis (Gutiérrez et al., 1997; Silva et al., 2006; Zheng et al., 2008), and cumulus cells are considered more progesteronic than mural granulosa cells when exposed to higher concentrations of FSH (Armstrong et al., 1996). Supplementation with $10 \mathrm{ng} / \mathrm{ml}$ of FSH was able to maintain higher levels of $17 \beta$-estradiol compared with progesterone (Zheng et al., 2008). MIV $\mathrm{B}+\mathrm{FSH}$ sustained the E2:P4 ratio at approximately 1.0, similar to the $0 \mathrm{FSH}$ medium; however, the absolute levels of both steroid hormones were higher in the FSH medium as expected.

The mRNA expression levels were differently regulated based on the presence or absence of FSH. 


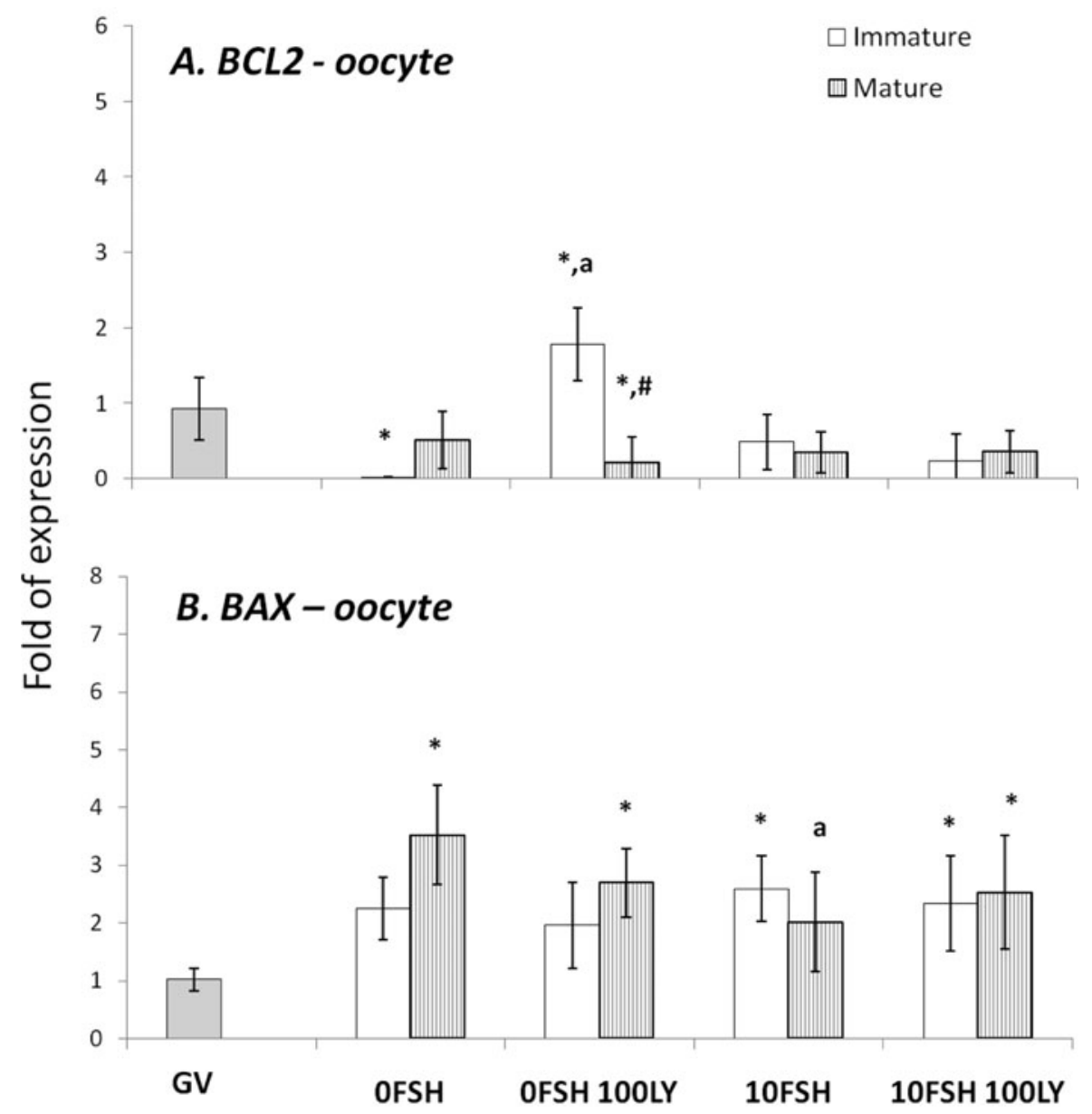

Figure $3 B A X$ and $B C L 2$ gene expression levels in mature and immature oocytes isolated from COCs after being cultured in a medium with or without FSH and the PI3K inhibitor, LY294002. * Indicates significantly different from GV $(P<0.05)$. ${ }^{a}$ Indicates significantly different from 0FSH group during the same cell status $(P<0.05)$. ${ }^{\#}$ Indicates significantly difference between immature and mature oocytes in the same experimental treatment.

Table 2 PI3K and FSH effects in 17 $\beta$-estradiol and progesterone concentrations and E2/P4 ratio of in vitro matured COCs

\begin{tabular}{|c|c|c|c|}
\hline & $0 \mathrm{FSH}$ & $10 \mathrm{FSH}$ & Significance \\
\hline \multicolumn{4}{|c|}{$17 \beta$-Estradiol (ng/ml) } \\
\hline 0 LY294002 & $7.26 \pm 2.47^{a}$ & $16.40 \pm 6.10^{a}$ & $P=0.008$ \\
\hline 10 нM LY294002 & $5.02 \pm 2.60^{a}$ & $14.26 \pm 3.67^{a}$ & $P=0.023$ \\
\hline $100 \mu \mathrm{M}$ LY294002 & $2.33 \pm 0.44^{b}$ & $5.33 \pm 2.60^{b}$ & $P=0.009$ \\
\hline \multicolumn{4}{|c|}{ Progesterone (ng/ml) } \\
\hline 0 LY294002 & $8.91 \pm 4.18^{a}$ & $27.06 \pm 10.72^{a}$ & $P=0.003$ \\
\hline 10 нM LY294002 & $16.13 \pm 1.50^{a}$ & $37.50 \pm 8.53^{a}$ & $P=0.012$ \\
\hline 100 нM LY294002 & $17.68 \pm 6.41^{b}$ & $38.04 \pm 11.26^{a}$ & $P=0.003$ \\
\hline \multicolumn{4}{|c|}{$17 \beta$-Estradiol/progesterone ratio (E2/P4 ratio) } \\
\hline 0 LY294002 & $1.23 \pm 0.95^{a}$ & $0.75 \pm 0.68^{a}$ & $P>0.05$ \\
\hline 10 нM LY294002 & $0.32 \pm 0.17^{a}$ & $0.40 \pm 0.14^{a}$ & $P>0.05$ \\
\hline $100 \mu \mathrm{M}$ LY294002 & $0.13 \pm 0.02^{b}$ & $0.13 \pm 0.06^{b}$ & $P>0.05$ \\
\hline
\end{tabular}

Significance expressed in the table is between 0FSH and 10FSH groups (Student's $t$-test).

${ }^{a, b}$ Letters indicates statistical difference between $0 \mu \mathrm{M}, 10 \mu \mathrm{M}$ and $100 \mu \mathrm{M}$ LY294002 [one-way analysis of variance (ANOVA), $P<0.05]$.

Two-way ANOVA indicates statistical difference between the profile of $0 \mathrm{FSH}$ and $10 \mathrm{FSH}$ in each dose of inhibitor in $17 \beta$-estradiol $(P=0.0007)$ and progesterone $(P<0.0001)$, but not in $\mathrm{E} 2 / \mathrm{P} 4$ ratio $(P>0.05)$. 


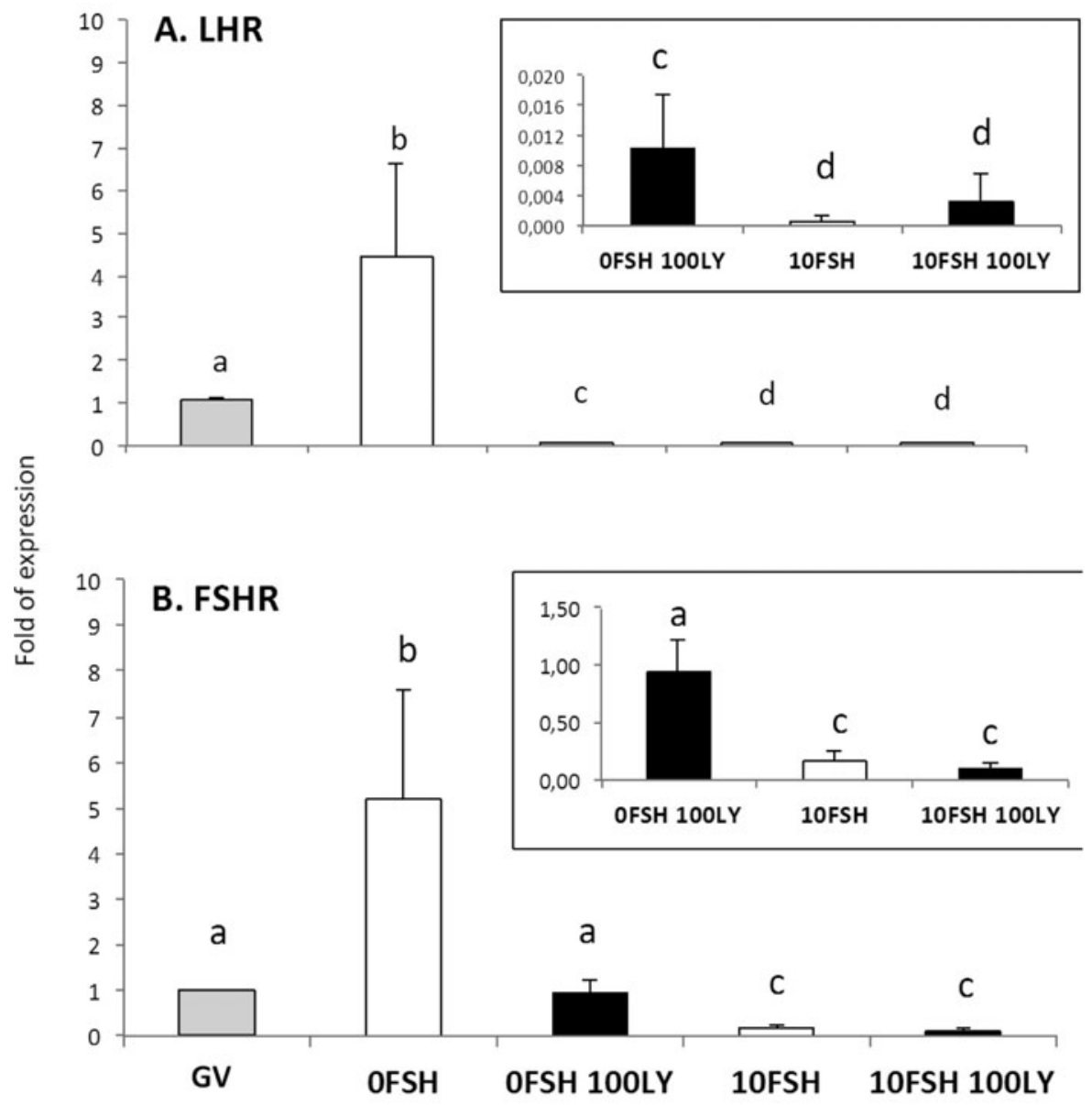

Figure 4 The roles of FSH and PI3K inhibition in the gene expression of the receptors of LH (LHR) and FSH (FSHR) in cumulus cells from bovine COCs cultured in vitro. ${ }^{\mathrm{a}, \mathrm{b}, \mathrm{c}, \mathrm{d}}$ Different letters indicate significant statistical differences among groups $(P<$ 0.05).

Exposure to FSH for $24 \mathrm{~h}$ decreased the expression levels of steroidogenic enzymes (with exception of CYP11A1) and gonadotropin receptors, despite the enhancement of steroidogenic activity, which was demonstrated by E2 and P4 concentrations. Culture medium that did not contain FSH sustained higher levels of LHR, FSHR, CYP11A1, CYP19A1 and HSD17B1 expression.

Steroid production depends on gonadotropins and enzymes, and previous studies have demonstrated that FSH controls the expression levels of CYP11A1, CYP19A1, HSD17B1, LHR and FSHR in COCs and granulosa cells (Silva \& Price, 2002; Calder et al., 2003; Sahmi et al., 2006). However, the gene expression levels of gonadotropins and enzymes are not directly related to hormone production. The lower levels of expression can be related to the downregulation of FSH receptors after $24 \mathrm{~h}$ of exposure to hormones (Houde et al., 1994) or the mRNA stability during culture (Sahmi et al., 2006; Payne, 2015). Cultured COCs showed decreased expression levels of the $F S H$ receptor, whereas the $L H$ receptor levels increased (Calder et al., 2003; Salhab et al., 2011). The levels of CYP11A1 and CYP19A1 decreased during culture (Salhab et al., 2011), and HSD17B1 expression in COCs has not been fully explored. In bovine granulosa cells, mRNA stability was observed for $3 \mathrm{~h}$ for CYP19A1 mRNA and for $12 \mathrm{~h}$ for CYP11A1 and HSD17B1 mRNAs (Sahmi et al., 2006).

In terms of intracellular signalling, PI3K has been extensively investigated in cancer cells, and its mutations are frequently identified in cancer cell lines and somatic cells (Yuan and Cantley, 2008; Liu et al., 2009), making this protein a pharmacological target (Liu et al., 2009, 2011). PI3K is one of the most relevant proteins that controls steroidogenesis (Moore et al., 2001; Shimada et al., 2003; Yu et al., 2005; Su et al., 2006; Ebeling et al., 2011) and has defined actions in the activation and survival of primordial follicles, and in the recruitment of follicles (Zheng et al., 2012).

PI3K controls steroidogenesis, an effect that has been observed by using $100 \mu \mathrm{M}$ of its inhibitor, LY294002, a dose used by Hoshino et al. (2004). The steroid 

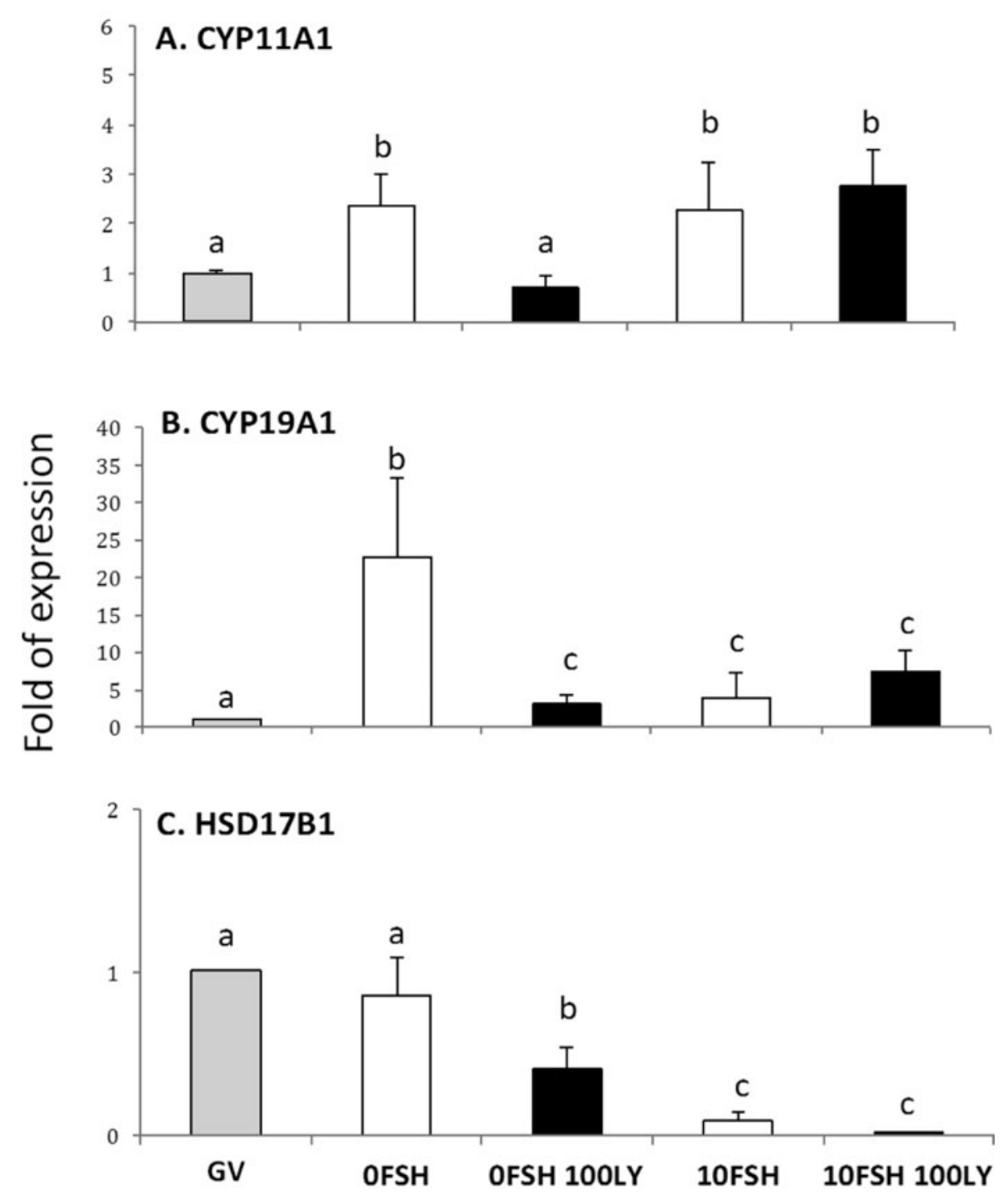

Figure 5 The roles of FSH and PI3K inhibition in the gene expression of the receptors of CYP11A1, CYP19A1 (aromatase) and HSD17B1 in cumulus cells from bovine COCs cultured in vitro. ${ }^{\mathrm{a}, \mathrm{b}, \mathrm{c}}$ Different letters indicate significant statistical differences among groups $(P<0.05)$.

concentrations in the culture medium after $24 \mathrm{~h}$ of culture indicate the relevance of PI3K, which decreases 17ß-estradiol and the E2:P4 ratio in the presence or absence of FSH. In the absence of FSH, progesterone production was significantly enhanced after PI3K inhibition. LY294002 caused a significant decrease in LHR, FSHR, CYP11A1, CYP19A1 and HSD17B1 expression levels in $0 \mathrm{FSH}$ medium but demonstrated no effects in 10FSH.

Previous results have indicated that, in the presence of $\mathrm{FSH}$, progesterone production is stimulated by LY294002 in cumulus cells (Shimada et al., 2003) and MAPK (protein controlled by PI3K) is inhibited, which indicates that progesterone levels decrease and estradiol levels increase in cumulus and granulosa cells (Moore et al., 2001; Yu et al., 2005; Su et al.,
2006; Ebeling et al., 2011). Our data demonstrated that steroidogenesis is dependent on, but not exclusively so, PI3K action because steroidogenesis occurs even in the presence of LY294002.

Previous results have shown that PI3K or MAPK inhibition, in the presence of FSH, resulted in differing effects on CYP11A1 and CYP19A1 gene expression levels in COCs and granulosa cells (Moore et al., 2001; Su et al., 2006; Ebeling et al., 2011), and no studies have reported the effects on FSHR, LHR and HSD17B1 gene expression levels. The lack of additional information about the relevance of PI3K to steroidogenic gene expression in COCs cultured in vitro makes the current study an important contribution to the understanding of oocyte maturation. It is noteworthy that steroidogenesis inhibitors (AGT) reduce the production of estradiol 


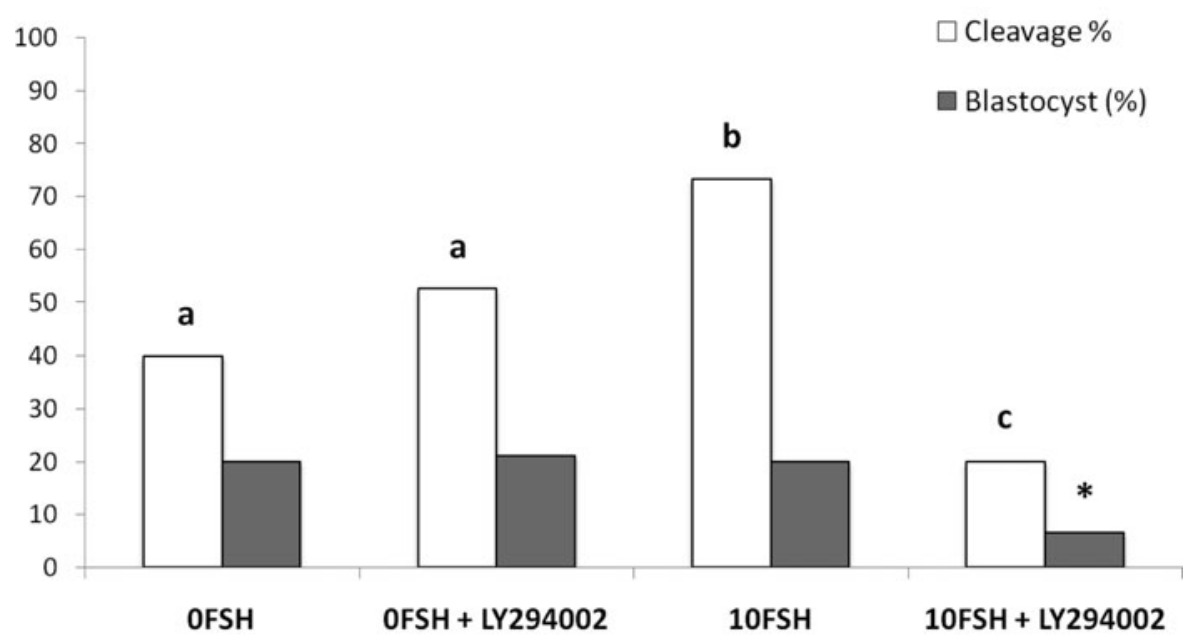

Figure 6 Cleavage and blastocyst rates of COCs after culture in the presence or absence of FSH and the PI3K inhibitor, LY294002. There were 168 oocytes, and 28 blastocyst embryos developed in vitro. The number of oocytes per replicate was 41 to 45 COCs, and the experiment was repeated three times. ${ }^{a, b, c}$ Different letters indicate significant statistical differences among groups $(P<$ 0.05). *Indicates significantly decreased compared with all groups.

and progesterone and, as expected, impair the in vitro maturation of COCs. Supplementation of both hormones did not recover maturation rates, which indicates that other relevant factors are involved (Wang et al., 2006).

In terms of in vitro embryo development, COCs cultured in the $0 \mathrm{FSH}$ medium developed to the blastocyst stage independently of the presence of LY294002, in accordance with the observations of Mota et al (2015). The 10FSH medium increased embryo cleavage but not blastocyst development, and COCs matured in vitro with LY294002 decreased both parameters. The inhibition of PI3K blocked the essential effects of FSH in oocyte competence, including embryo development in vitro, despite the expression levels of $B A X$ and $B C L 2$. The inability to extrude polar bodies can be associated with low-quality embryos, lower in vitro development and genomic aberrations (Somfai et al., 2005). The concentration of $17 \beta$-estradiol in the culture medium was also lower in the group 10FSH 100LY, indicating some possible correlation.

In conclusion, the relevance of FSH and PI3K to COC maturation is essential as observed by polar body extrusions, steroidogenesis and embryo development in vitro, although the gene expression levels were not directly related to oocyte competence and blastocyst rates.

\section{Acknowledgements}

The authors would like to thank CNPq and FAP-DF $(193.000 .577 / 2009)$ for grants. We would also like to thank Ponte Alta abattoir for supplying the ovaries and
Isabela Bessa, Silene Silva, Raul Holanda and Daniele Cristiane for their collaboration on the experiments and projects.

\section{Supplementary material}

To view supplementary material for this article, please visit https:/ / doi.org/10.1017/S0967199417000703

\section{Conflicts of interest}

The authors claim that there are no conflicts of interest.

\section{Funding}

Conselho Nacional de Desenvolvimento Científico e Tecnológico $(\mathrm{CNPq})$ and Fundação de Apoio à Pesquisa do Distrito Federal (FAP-DF) (193.000.577/2009), Brazil.

Danielle Kaiser de Souza was the recipient of a Coordenação de Aperfeiçoamento de Pessoal de Nível Superior (CAPES) fellowship from the Medical Sciences Program/University of Brasilia.

\section{Supporting information}

Additional Supporting information is available online at the publisher's website. 
Figure S1 Viability test of COC after culture in the presence or absence of FSH and the PI3K inhibitor, LY294002.

\section{References}

Aardema, H., Roelen, B.A., van Tol, H.T., Oei, C.H., Gadella, B.M. \& Vos, P.L. (2013). Follicular 17ß-estradiol and progesterone concentrations and degree of cumulus cell expansion as predictors of in vivo-matured oocyte developmental competence in superstimulated heifers. Theriogenology 80, 576-83.

Armstrong, D.T., Xia, P., de, Gannes, G., Tekpetey, F.R. \& Khamsi, F. (1996). Differential effects of insulin-like growth factor-I and follicle-stimulating hormone on proliferation and differentiation of bovine cumulus cells and granulosa cells. Biol. Reprod. 54, 331-8.

Beker, A.R., Colenbrander, B. \& Bevers, M.M. (2002). Effect of 17beta-estradiol on the in vitro maturation of bovine oocytes. Theriogenology 58, 1663-73.

Calado, A.M., Rocha II, E., Colaço, A. \& Sousa, M. (2005). Estudo estereológico comparativo de complexos cumulusovócito aspirados de folículos durante o ciclo estral em bovinos. Arq. Bras. Med. Vet. Zootec. 57, 465-475.

Calder, M.D., Caveney, A.N., Smith, L.C. \& Watson, A.J. (2003). Responsiveness of bovine cumulus-oocytecomplexes (COC) to porcine and recombinant human FSH, and the effect of COC quality on gonadotropin receptor and $\mathrm{C} \times 43$ marker gene mRNAs during maturation in vitro. Reprod. Biol. Endocrinol. 11, 1-14.

Ebeling, S., Töpfer, D. \& Meinecke, B. (2011). Steroidogenesis and the influence of MAPK activity during in vitro maturation of porcine cumulus-oocyte complexes. Reprod. Domest. Anim. 46, 513-9.

Engelman, J.A., Luo, J. \& Cantley, L.C. (2006). The evolution of phosphatidylinositol 3-kinases as regulators of growth and metabolism. Nat. Rev. Genet. 7, 606-19.

Ferreira, E.M., Vireque, A.A., Adona, P.R., Meirelles, F.V., Ferriani, R.A. \& Navarro, P.A. (2009). Cytoplasmic maturation of bovine oocytes: structural and biochemical modifications and acquisition of developmental competence. Theriogenology 71, 836-48.

Gulart., L.V.M. (2015). Meios de cultivo para maturação de oócitos e produção de embriões avaliados por marcadores moleculares. http://repositorio.unb.br/handle/ 10482/19064 Accessed 28 January 2017.

Gutiérrez, C.G., Campbell, B.K. \& Webb, R. (1997). Development of a long-term bovine granulosa cell culture system: induction and maintenance of estradiol production, response to follicle-stimulating hormone, and morphological characteristics. Biol. Reprod. 56, 608-16.

Hawkins, P.T., Anderson, K.E., Davidson, K. \& Stephens, L.R. (2006). Signalling through Class I PI3Ks in mammalian cells. Biochem. Soc. Trans. 34( Pt 5), 647-62.

Hoshino, Y., Yokoo, M., Yoshida, N., Sasada, H., Matsumoto, H. \& Sato, E. (2004). Phosphatidylinositol 3-kinase and Akt participate in the FSH-induced meiotic maturation of mouse oocytes. Mol. Reprod. Dev. 69, 77-86.

Houde, A., Lambert, A., Saumande, J., Silversides, D.W. \& Lussier, J.G. (1994). Structure of the bovine follicle- stimulating hormone receptor complementary DNA and expression in bovine tissues. Mol. Reprod. Dev. 39, 127-35.

Kempisty, B., Woźna, M., Piotrowska, H., Bukowska, D., Jackowska, M., Antosik, P., Jaśkowski, J.M. \& Brüssow, K.P. (2012). The expression of genes encoding zona pellucida glycoproteins in canine cumulus-oocyte complexes cultured in vitro in medium supplemented with progesterone and estradiol. Theriogenology 77, 684-93.

Kubo, N., Cayo-Colca, IS. \& Miyano, T. (2015). Effect of estradiol-17 $\beta$ during in vitro growth culture on the growth, maturation, cumulus expansion and development of porcine oocytes from early antral follicles. Anim. Sci. J. 86, 251-9.

Li, H., Wang, B., Zhu, C., Feng, Y., Wang, S., Shahzad, M., Hu, C., Mo, M., Du, F. \& Yu, X. (2013a). 17ß-Estradiol impedes bax-involved mitochondrial apoptosis of retinal nerve cells induced by oxidative damage via the phosphatidylinositol 3-kinase/Akt signal pathway. J. Mol. Neurosci. 50, 482-93.

Li, J., Wu, H., Xue, G., Wang, P. \& Hou, Y. (2013b). $17 \beta$-Oestradiol protects primary-cultured rat cortical neurons from ketamine-induced apoptosis by activating PI3K/Akt/Bcl-2 signalling. Basic Clin. Pharmacol. Toxicol. 113, 411-8.

Liu, P., Cheng, H., Roberts, TM. \& Zhao, J.J. (2009). Targeting the phosphoinositide 3-kinase pathway in cancer. Nat. Rev. Drug Discov. 8:627-44.

Liu, P., Cheng, H., Santiago, S., Raeder, M., Zhang, F., Isabella, A., Yang, J., Semaan, D.J., Chen, C., Fox, E.A., Gray, N.S., Monahan, J., Schlegel, R., Beroukhim, R., Mills, G.B. \& Zhao, J.J. (2011). Oncogenic PIK3CA-driven mammary tumors frequently recur via PI3K pathway-dependent and PI3K pathway-independent mechanisms. Nat. Med. 17, 1116-20.

Mani, A.M., Fenwick, M.A., Cheng, Z., Sharma, M.K., Singh, D. \& Wathes, D.C. (2010). IGF1 induces upregulation of steroidogenic and apoptotic regulatory genes via activation of phosphatidylinositol dependent kinase/ AKT in bovine granulosa cells. Reproduction 139, 139-51.

Moore, R..K., Otsuka, F. \& Shimasaki, S. (2001). Role of ERK1/2 in the differential synthesis of progesterone and estradiol by granulosa cells. Biochem. Biophys. Res. Commun. 289, 796-800.

Morgan, S., Campbell, L., Allison, V., Murray, A. \& Spears, N. (2015). Culture and co-culture of mouse ovaries and ovarian follicles. J. Vis. Exp. 97, e52458.

Mota, G.B., Oliveira e Silva, I., de Souza, D.K., Tuany, F., Pereira, M.M., Camargo, L.S. \& Rosa e Silva, A.A. (2015). Insulin influences developmental competence of bovine oocytes cultured in $\alpha$-MEM plus follicle-simulating hormone. Zygote 23, 563-72.

Pawlak, P., Warzych, E., Hryciuk, M. \& Lechniak, D. (2015). Transcript abundance, glutathione and apoptosis levels differ between porcine oocytes collected from prepubertal and cyclic gilts. Theriogenology 84, 86-93.

Payne, S.H. (2015). The utility of protein and mRNA correlation. Cell 40, 1-3.

Sahmi, M., Nicola, E.S. \& Price, C.A. (2006). Hormonal regulation of cytochrome P450 aromatase mRNA stability in non-luteinizing bovine granulosa cells in vitro. J. Endocrinol. 190, 107-15. 
Salhab, M., Tosca, L., Cabau, C., Papillier, P., Perreau, C., Dupont, J., Mermillod, P. \& Uzbekova, S. (2011). Kinetics of gene expression and signaling in bovine cumulus cells throughout IVM in different mediums in relation to oocyte developmental competence, cumulus apoptosis and progesterone secretion. Theriogenology 75, 90-104.

Shimada, M., Ito, J., Yamashita, Y., Okazaki, T. \& Isobe, N. (2003). Phosphatidylinositol3-kinase in cumulus cells is responsible for both suppression of spontaneous maturation and induction of gonadotropin-stimulated maturation of porcine oocytes. J. Endocrinol. 179, 25-34.

Silva, J.M. \& Price, CA. (2002). Insulin and IGF-1 are necessary for FSH-induced cytochrome P450 aromatase but not cytochrome P450 side-chain cleavage gene expression in oestrogenic granulosa cells in vitro. J. Endocrinol. 174, 499507.

Silva, J.M., Hamel, M., Sahmi, M. \& Price, C.A. (2006). Control of oestradiol secretion and of cytochrome P450 aromatase messenger ribonucleic acid accumulation by FSH involves different intracellular pathways in oestrogenic bovine granulosa cells in vitro. Reproduction 132, 909-17.

Somfai, T., Kikuchi, K., Medvedev, S., Onishi, A., Iwamoto, M., Fuchimoto, D., Ozawa, M., Noguchi, J., Kaneko, H., Ohnuma, K., Sato, E. \& Nagai, T. (2005). Development to the blastocyst stage of immature pig oocytes arrested before the metaphase-II stage and fertilized in vitro. Anim. Reprod. Sci. 90(3-4), 307-28.

Stocco, C. (2008). Aromatase expression in the ovary: hormonal and molecular regulation. Steroids 73, 473-87.

Su, Y.Q., Nyegaard, M., Overgaard, M.T., Qiao, J. \& Giudice, L.C. (2006). Participation of mitogen-activated protein kinase in luteinizing hormone-induced differential regulation of steroidogenesis and steroidogenic gene expression in mural and cumulus granulosa cells of mouse preovulatory follicles. Biol. Reprod. 75, 859-67.

Vanhaesebroeck, B., Guillermet-Guibert, J., Graupera, M. \& Bilanges, B. (2010). The emerging mechanisms of isoformspecific PI3K signalling. Nat. Rev. Mol. Cell. Biol. 11, 329-41.

Vasconcelos, R.B., Salles, L.P., Oliveira e Silva, I., Gulart, L.V., Souza, D.K., Torres, FA., Bocca, A.L. \& Rosa e Silva, A.A. (2013). Culture of bovine ovarian follicle wall sections maintained the highly estrogenic profile under basal and chemically defined conditions. Braz. J. Med. Biol. Res. 46, 700-7.

Viana, J.H., De Almeida, Camargo, L.S., De Moraes Ferreira, A., De Sa, W.F., De Carvalho Fernandes, C.A. \& De Pinho Marques Jr, A. (2004). Short intervals between ultrasonographically guided follicle aspiration improve oocyte quality but do not prevent establishment of dominant follicles in the Gir breed (Bos indicus) of cattle. Anim. Reprod Sci. 84(1-2), 1-12.

Wang, H.F., Isobe, N., Kumamoto, K., Yamashiro, H., Yamashita, Y. \& Terada, T. (2006). Studies of the role of steroid hormone in the regulation of oocyte maturation in cattle. Reprod. Biol. Endocrinol. 4, 4.

Yu, F.Q., Han, C.S., Yang, W., Jin, X., Hu, Z.Y. \& Liu, Y.X. (2005). Activation of the p38 MAPK pathway by follicle-stimulating hormone regulates steroidogenesis in granulosa cells differentially. J. Endocrinol. 186, 85-96.

Yuan, T.L. \& Cantley, L.C. (2008). PI3K pathway alterations in cancer: variations on a theme. Oncogene 27, 54975510.

Zhang, H. \& Liu, K. (2015). Cellular and molecular regulation of the activation of mammalian primordial follicles: somatic cells initiate follicle activation in adulthood. Hum. Reprod. Update 21, 779-86.

Zheng, P., Baibakov, B., Wang, X.H. \& Dean, J. (2013). PtdIns(3,4,5)P3 is constitutively synthesized and required for spindle translocation during meiosis in mouse oocytes. J. Cell. Sci. 126( Pt 3), 715-21.

Zheng, P., Si, W., Bavister, B.D., Yang, J., Ding, C. \& Ji, W. (2003). 17Beta-estradiol and progesterone improve in vitro cytoplasmic maturation of oocytes from unstimulated prepubertal and adult rhesus monkeys. Hum. Reprod. 18, 2137-44.

Zheng, W., Nagaraju, G., Liu, Z. \& Liu, K. (2012). Functional roles of the phosphatidylinositol 3-kinase (PI3Ks) signaling in the mammalian ovary. Mol. Cell. Endocrinol 356(1-2), 24-30.

Zheng, X., Price, CA., Tremblay, Y., Lussier, J.G. \& Carrière, P.D. (2008). Role of transforming growth factor-beta1 in gene expression and activity of estradiol and progesteronegenerating enzymes in FSH-stimulated bovine granulosa cells. Reproduction 136, 447-57. 